\title{
VS1 型真空断路器的典型故障分析及预防措施探讨
}

\section{Analysis of Typical Faults of VS1 Vacuum Circuit Breaker and Discussion on Preventive}

\author{
Measures \\ 白晶晶 ${ }^{1}$ 刘昊洁 $^{2}$ 张东亮 $^{1}$ 白庆永 ${ }^{1}$ \\ Jingjing Bai ${ }^{1}$ Haojie Liu ${ }^{2}$ Dongliang Zhang ${ }^{1}$ Qingyong Bai ${ }^{1}$
}

1.国网冀北电力有限公司廊坊供电公司 中国·河北 廊坊 065000 ;

\section{2.北京城区供电公司}

中国·北京 100034

1.State Grid Jibei Power Co., Ltd.

Langfang Power Supply Company,

Langfang, Hebei, 065000, China;

2.Beijing City Power Supply Company,

Beijing, 100034, China
【摘要】论文重点介绍变电站常见的 VS1 型真空断路器的组成和结构工作原理, 并结合 二次回路图分析了开关柜出现合闸失败、分闸失败、储能故障以及防误闭锁装置故障的原 因。针对检修工作提出了降低断路故障发生率的措施。

【Abstract】This paper mainly introduces the composition and structure working principle of VS1 type vacuum circuit breaker which is commonly used in substation, and analyzes the energy storage failure of closing failure of opening failure of switch cabinet and the causes of anti-lock failure by combining with the secondary circuit diagram.

【关键词】断路器; 合闸; 闭锁; 线圈

【Keywords 】circuit breaker; closing; latching; coil

【DOI】10.36012/peti.v2i1.1305

\section{VS1 型断路器的结构}

高压断路器安装在断路器室内。正常供电时断路器通过 负荷电流, 当出现短路、接地或严重过负荷故障时, 继电保护 装置与断路器配合, 将故障电流快速切断。断路器由底盘车、 极柱、触臂、动触头、框架及内部机构组成。

\section{2 断路器的工作原理}

断路器的操动机构主要有液压式、弹簧式、弹簧储能液压 式和电磁式几种 ${ }^{[1]}$ 。以弹簧储能操动机构为例, 它的机械式操 动机构以弹簧储能为基本原理。开断时,弹簧释放能量的同时 带动机械传递单元使触头运动实现分合闸。

储能阶段电动机以及减速装置通过带动储能机构使合闸 弹簧储能, 储能完成后通过锁扣装置使弹簧保持在储能状态。 储能完成后, 行程开关被触发, 电机停转, 停止储能。合闸阶段 合闸线圈通电, 通过铁芯运动使合闸锁扣装置解锁, 合闸弹簧 的能量释放。这些能量一部分通过传动机构带动断路器的动 触头合闸, 另一部分使分闸弹簧储能。重新储能阶段合闸之 后, 行程开关被触发, 储能电动机立即接通电源, 使合闸弹簧 再次储能,准备下一次合闸。

分闸阶段分闸线圈得电，分闸电磁铁动作使分闸锁扣装 置解锁, 分闸弹簧将能量释放, 带动触头实现分闸。

\section{VS1 断路器的典型故障分析}

断路器部分的故障可能出现在合闸回路、分闸回路、闭锁 回路、弹簧储能部分。

\section{1 合闸失败}

从合闸回路的二次图来看 (如图 1 所示), 当空气开关 $1 D K$ 、整流块 $\mathrm{V} 2$ 、防跳跃继电器 $\mathrm{KO}$ 、合闸线圈 $\mathrm{HQ}$ 、合闸按钮 $\mathrm{SA}$ 、辅助开关 $\mathrm{QF}$ 、微动开关 $\mathrm{S} 3$ 、航空插头 $\mathrm{T}$ 等任何一部分出 现故障都可能导致合闸失败。因此, 当断路器出现合闸失败 时,分析有以下几种可能的原因:

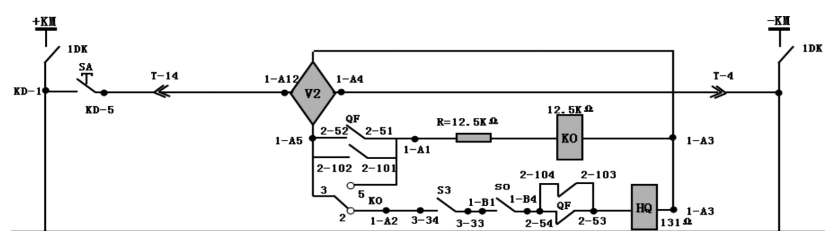

图 1 合闸回路

(1)空气开关 $1 \mathrm{DK}$ 故障。检查各触点接线和触点的接触情 况是否良好。如接触不良可考虑更换接点接线。

(2)控制电路板 (整流块 V2)内合闸回路故障。检查接触 器、熔断器是否有烧损、熔断的情况, 电路板接线有无松动等。

(3)合闸线圈 HQ。检查合闸线圈, 若合闸线圈出现烧坏、 脱落或卡涩的情况时, 将直接造成断路器合闸失败。此时应用 
万用表测合闸线圈的阻值, 如阻值偏离正常值, 过大或过小, 则应更换合闸线圈。

(4)合闸按钮 SA、辅助开关 $Q F$ 、微动开关 $S 3$ 接触不良。检 查各触点接线和触点的接触情况是否良好。如接触不良可考 虑更换接点接线或者调整行程开关的接触位置。

(5)航空插头 $\mathrm{T}$ 接触不良。应首先检查插针接线柱有无松 动或脱落情况, 如有松动情况应予以焊接, 如插针焊接良好, 应插拔固定好再合闸。

(6)手车没摇到位置。此时手车位置指示灯灭, 用操作把手 调整手车位置, 检查指示灯亮。

(7)没有控制或储能电源。检查控制电源开关是否在合位。 如果储能指示灯灭, 提示弹簧未储能, 检查储能电源开关是否 合到位。

(8)机械原因。检查机构箱内滚针轴承是否损坏。如损坏将 造成凸轮压不到合闸滚轮, 连杆不动作, 断路器合闸失败。

\section{2 分闸失败}

从分闸回路的二次图来看 (如图 2 所示), 当断路器出现 分闸失败时, 分析有以下几种可能的原因:

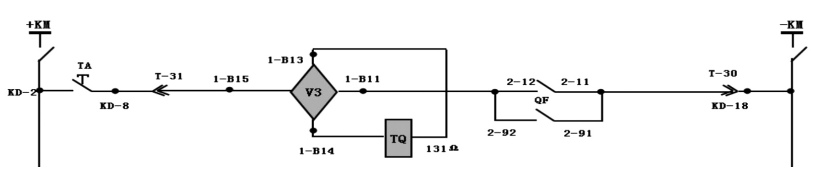

图 2 分闸回路

(1)空气开关 $1 \mathrm{DK}$ 故障。检查各触点接线和触点的接触情 况是否良好。如接触不良可考虑更换接点接线。

(2)控制电路板(整流块 V3) 内分闸回路故障。检查接触 器、熔断器是否有烧损、熔断的情况, 电路板接线有无松动等。

(3)分闸线圈 TQ。检查分闸线圈, 若分闸线圈出现烧坏、脱 落或卡涩的情况时, 将直接造成断路器分闸失败。此时应用万 用表测分闸电磁铁线圈的阻值, 如阻值偏离正常值, 过大或过 小,则应更换分闸线圈。

(4)分闸按钮 $\mathrm{TA}$ 、辅助开关 $\mathrm{QF}$ 接触不良。检查开关的接 触情况和开关内部触点。

(5)航空插头 $\mathrm{T}$ 接触不良。应首先检查插针接线柱有无松 动或脱落情况, 如有松动情况应予以焊接, 如插针焊接良好, 应插拔固定好再分闸。

\section{3 闭锁回路故障}

断路器闭锁回路的故障表现为电动合闸拒合、手动合闸 拒合。当断路器出现电动合闸拒合、手动合闸拒合时, 分析有 以下几种可能的原因:

(1) 空气开关 $1 \mathrm{DK}$ 故障。检查各触点接线和触点的接触情 况是否良好。如接触不良可考虑更换接点接线。

(2)控制电路板(整流块 V1) 内闭锁回路故障。检查接触
器、熔断器是否有烧损、熔断的情况, 电路板接线有无松动等。

(3)闭锁线圈 $\mathrm{Y} 1$ 。检查闭锁线圈, 若闭锁线圈出现烧坏、脱 落或卡涩的情况时, 将直接造成闭锁回路故障。此时应用万用 表测闭锁电磁铁线圈的阻值, 如阻值偏离正常值, 过大或过 小,则应更换闭锁线圈。

(4)辅助开关 $\mathrm{QF}$ 接触不良。检查开关的接触情况和开关 内部触点。

(5)航空插头 $\mathrm{T}$ 接触不良。应首先检查插针接线柱有无松 动或脱落情况, 如有松动情况应予以焊接, 如插针焊接良好, 应插拔固定好。

\section{4 断路器储能故障}

断路器的储能故障表现为电动不储能手动储能、电动可 以储能手动不储能、储能完电机不停转几种情况。当断路器出 现储能问题时,分析有以下几种可能的原因:

(1)电动不储能手动储能。可能由于控制电路板（整流块 V4) 内储能回路熔断器熔断。检查接触器、熔断器是否有烧 损、熔断的情况，电路板接线有无松动等。储能电机短路或断 路时也可能导致电动不储能。用万用表测量电机的阻值, 如异 常给与更换。检查微动开关、辅助开关、空气开关等的接触情 况和开关内部触点, 检查辅助开关是否接触不良。

(2)电动可以储能手动不储能。出现此故障的原因是机械故 障, 即蜗轮内单相轴承失效。此时使用手动储能小链轮不动作。

(3)储能完成后电机不停转。出现此故障的原因是辅助开 关切换不到位。

\section{4 减少断路故障发生率的措施}

(1)断路器一旦出现故障, 应尽量减少其操作次数,防止因 为触头接触不良电阻过大造成的触头过热甚至爆炸等事故。 每年小修时, 应对绝缘件表面和断路器外壳进行清扫, 并检查 螺丝有无松动脱落现象 ${ }^{[2]}$ 。

(2)对于机械操动和传动机构, 应在接触和转动部分加适 量的润滑油,保证机构运动自如。

(3)对于开断电流次数达到规定值或使用时间达到 20 年的 断路器, 应对其灭弧室的真空度进行认真检测, 必要时更换。

(4)应适时结合小修复测行程和超行程, 并进行动作电压 和动作时间的测量。

(5)定期对断路器的绝缘系统进行试验检查，如结合大修 或每 1 3 年进行一次交流耐压试验。

\section{参考文献}

[1]杨毅征.变电检修技术及其注意事项[J].中国高新技术企业， 2015(14):146-147.

[2]包卫军.综述变电检修中存在的问题及解决措施 [J].科技与企 业,2013(18):314-315。 